\title{
OBSERVATIONS ON THE BIOLOGY OF THE IXODIDAE.
}

\author{
PART III. DEALING WITH THE BEHAVIOUR OF THE SEXES IN \\ AMBLYOMMA HEBRAEUM, HYALOMMA AEGYPTIUM AND RHIPI. \\ CEPHALUS BURSA WHEN UPON THE HOST.
}

By GEORGE H. F. NUTTALL, F.R.S.

THE experiments herein recorded were conducted with a view to supplementing the biological studies on ticks previously published by me in Parasitology, Vols. VI and vII, and, more particularly, to acquire a knowledge of the behaviour of the sexes upon the host. For this purpose, ticks belonging to three different genera were employed, i.e. Amblyomma, Hyalomma and Rhipicephalus, since their behaviour was likely to differ more widely than in members of one genus, although some members of the recognised genera, as I am perfectly aware, may differ still more widely in their habits than do the species to which this communication relates.

METHODS.

The adult ticks were placed upon a ram's scrotum enclosed in a canvas bag of suitable size which could be tightened at the neck by drawstrings running in opposite directions through a seam at the top of the bag. Furthermore the latter was secured by two cords that ran belt-wise around the animal. That the behaviour of the ticks in this confined area is practically the same as when they are permitted to roam at will upon the host was amply proved in my earlier experiments.

The ticks were given identification marks by painting a part of their backs with various colours. The paints, consisting of different kinds of sealing wax dissolved in alcohol, were applied to the ticks by means of a sharply pointed match. The alcohol evaporated soon after the paint was applied, and the hard glossy crust of wax that was formed in no way affected the ticks adversely. The colours had to be reapplied from time to time and no confusion of individuals resulted by the use of the method, except in some cases with $R$. bursa males, to whose smooth glossy backs the wax adhered badly.

Coloured lines were drawn with greased pencil upon the surface of the scrotum, front and back, whereby it was divided into areas which facilitated 
the recording of the ticks' wanderings from one seat of attachment to another. A record was mapped upon a daily chart, the signs of and $q$, pointing in different directions and variously coloured, denoting the exact position of individual ticks on successive days. The distances traversed by the ticks in their wanderings were mostly recorded approximately.

\section{AMBLYOMMA HEBRAEUM.}

The general biology of this species has already been described by me (1915, Parasitology, vI. pp. 409-419), it being stated (Ibid. p. 414) that Lounsbury is the only author who refers to the behaviour of the sexes upon the host. The observations here recorded amplify those of Lounsbury, which are but cursorily treated by this author.

The adults (Lot N. 1732) used in the following experiments belonged to the same strain that was employed in my earlier studies (loc. cit.). They had emerged on 9. xii. 1913. There were 167 o $\delta$ and 95 qo alive on 25. i. 1915, i.e. after having been kept unfed at room temperature for 412 days. A number of these ticks were placed successively on a ram's scrotum as follows:

$\begin{array}{cccc} & \begin{array}{c}\text { Day recorded } \\ \text { in protocol }\end{array} & \text { o } & \text { \% } \\ \text { On 25. i. 1915 } & 1 & 12 & - \\ & 4 & - & 13 \\ & 10 & - & 5 \\ 12 & - & 2 \\ & 16 & 2 & - \\ & 23 & - & 4 \\ & 39 & - & 6 \\ & \text { Totals } & 14 & 30\end{array}$

Of these ticks, one $\sigma^{\prime}$ (No. 12) was lost after three days and two of? (Nos. 29, 30) disappeared. The following record relates therefore to 13 o $\sigma^{*}$ and 28 웅, and their behaviour upon the host on successive days:

Records relating to A. hebraeum Males Nos. 1-14.

$\delta$ 1. Days 1-10 fixed*; on 11 th joined by $q 8$ which dropped $\dagger$ on 20 th, the $\delta$ continuing fixed; on 36th he rotates $45^{\circ}$; on 37 th he appears excited; on 39 th he shifts ca. $2 \mathrm{~mm}$. from his original seat of attachment (a distinct crater); he is excited on $42 \mathrm{nd}, 47 \mathrm{th}$; removed on 132nd day.

O 2. Days 1-10 fixed; on 11 th joined by $q 12$ which dropped on 20th; he is approached on 20 th by $Q$ 18; on 21 st he is joined by $q 18$ which dropped on $29 \mathrm{th}$; he is excited on days 29,30 , $33,36,37$; +23 is put to him on 39th and stays with him till she dropped on 50 th; he is excited on days $50,54,57$; remains fixed to 141 st day.

* The term "fixed" denotes that the tick remained attached immovably at one spot.

$\dagger$ Meaning dropped off the host in an engorged condition. 
53. Days 1-11 fixed; on 1Ith put to him 97 , but she did not stay; on 12th 99 joined him and dropped 21st; on 23rd put to him 919 which dropped on 31st; he continues fixed, appearing excited on days 35-37; on 39th put to him 94 which dropped 50 th; he is excited on days 50,54 ; on 57 th he shifts a few $\mathrm{mm}$. and thereafter remains fixed to 141 st day.

o 4. Days 1-12 fixed; on 12th put to him $q 13$ which dropped on 22nd; on 23rd put to him $q 20$ which dropped on 33rd; he is excited on days 35-37, 39; on 39th put to him ? 25 which dropped on 48th; he is excited on days 51, 54,57, but remains fixed to 14lst day.

ơ 5. Days 1-12 fixed; on 12th put to him ㅇ 7 which dropped on 21st; he is exeited on 23rd when $\uparrow 29$ is put to him but she disappeared 24 th; on $23 \mathrm{rd} \mathrm{he} \mathrm{shifts} \mathrm{ca.} 1 \mathrm{~cm}$. and is excited on days $32,38,50$; on 57 th he shifts $3 \mathrm{~mm}$; he is removed 77 th day to illustrate his changed coloration.

స 6. Days 1-5 fixed; on 6th shifts slightly; on 12th put to him $ᄋ$ 14 which dropped 22nd; on 30 th put to him 22 which dropped 32 nd ; he is excited on days $33,35,38$; on 39 th put to him + 30 , she was lost on 40 th ; he is excited on days 50, 51; on 54th he shifts $6 \mathrm{~mm}$. and then remains fixed to 141 st day.

37. Days 1-11 fixed; on 11th put to him 911 ; on 31st he is found loose and wandering $4 \mathrm{~cm}$. away, he is seized and put to $q 11$ with which he copulates and stays till she dropped on 37 th when he wanders to posterior surface of scrotum and anchors close to males 10 and 12 ; on 38 th he is excited; on 49th he shifts slightly; on 50th he wanders freely and on 51 st is found dead.

o 8. Days 1-6 fixed; on 6th find 91 alongside, she dropped 22nd; on 23rd he is excited and put to him 921 which dropped on 32nd; he is alone and excited on days 32, 35-38; on 39th put to him 926 ; the pair shifts together on $40 \mathrm{th}$ about $1 \mathrm{~cm}$. and female is seen to drop on $49 \mathrm{th}$; on 50 th he is excited; on 57th he shifts $8 \mathrm{~mm}$. and remains fixed thereafter until removed on 132nd day.

39. Days 1-6 fixed; on 8th 95 approaches to within $5 \mathrm{~mm}$. of him and stays there till 10 th; on 11th copula, the pair having shifted together ca. $1 \mathrm{~cm}$; on 12th the pair in copula; female dropped on 18th; he is much excited on days 18, 19; on 20 th $q 15$ pairs with him, she dropped 29th; he is excited on days $31-33,37,38,40,44-46,50-54,56-58,60,77$; on 52 nd he shifts $7 \mathrm{~mm}$. but remains fixed thereafter until removed on 132nd day.

o 10. Days 1-9 fixed; on 9th find $q 6$ venter to venter with him, she becomes fully engorged but on 25th he leaves her and reattaches himself $5 \mathrm{~mm}$. away, she dropped on 26th; on 29th he shifts $13 \mathrm{~mm}$. to push away of 11 and join 916 then 1 gorged; this female is torn loose accidentally on 31st; he is excited on days 31, 33, 36-38, 45; on 49th +28 is found to have come a distance of $3 \mathrm{~cm}$. to join him, he having shifted his anchorage $5 \mathrm{~mm}$., the pair in copula. On 52nd he is excited, alongside the same female, the latter dropped on 56th; he is excited on days 56, 58; on 99th he shifts ca. $5 \mathrm{~mm}$., and thereafter remains fixed till removed on 132nd day.

o 11. Days 1-10 fixed; on 11th find $\subsetneq 10$ alongside him, she dropped 20th; on 21 st he is still fixed; on 22nd he is joined by 916 , copula seen; on $29 \mathrm{th}$, whilst the female is 1 gorged, he is crowded away by $\sigma^{\star} 10$, the female being accidentally torn off on 31st; he is excited on days $30-31,33,36-7,45-6,52,54,56-58,77$, but remains fixed till removed on 132nd day.

ô 12. Days 1-3 fixed, afterwards lost.

o 13. Put to $\bigcirc 4$ on day 16 ; on 19 th he shifts $3 \mathrm{~mm}$. away from female, but on 21 st is found elose to her again, she dropped $35 \mathrm{th}$; he is excited on days $40-45,50,52,54$, he shifts $5 \mathrm{~mm}$. on 57 th, is excited on 58th and shifts slightly on 99th, after which he remains fixed till removed on 132nd day.

б 14. Put to 92 on day 16, she dropped 22nd and he shifts $5 \mathrm{~cm}$.; on 28th he shifts $15 \mathrm{~mm}$.; he is excited on days 29,37 ; on 40 th he is joined by $q 27$ which dropped on 49 th ; he remains fixed, is excited on days $52,54,56$, but does not change anchorage till removed on 132nd day. 
Records relating to $A$. hebraeum Females Nos. 1-28.

\begin{tabular}{|c|c|c|c|c|c|c|c|}
\hline & $\begin{array}{l}\text { Day when } \\
\text { put on ram }\end{array}$ & $\begin{array}{l}\text { Day on which \& was } \\
\text { sought or put to } \delta\end{array}$ & $\begin{array}{l}\text { Feeding of } q \text { on } \\
\text { successive days } \\
\text { b. =began to feed } \\
\text { f. }=\text { fully gorged } \\
\text { g. }=\text { gorged }\end{array}$ & $\begin{array}{l}\text { idropped } \\
\text { off ram on } \\
\text { day }\end{array}$ & $\begin{array}{l}\text { q ceased } \\
\text { oviposit- } \\
\text { ing on } \\
\text { day }\end{array}$ & $\begin{array}{l}\text { Eggs } \\
\text { began to } \\
\text { hatch on } \\
\text { day }\end{array}$ & $\begin{array}{c}\text { Remarks } \\
\text { (h. =hatched) }\end{array}$ \\
\hline 운 & 4 & 6 sought $\$ 8$ & $\begin{array}{l}9 \text { b., } 18 \frac{1}{3}-g ., 19 \frac{1}{2}-g ., \\
20-21 \text { f. }\end{array}$ & 22 & - & 一 & few eggs, none $h$. \\
\hline 2 & 4 & $\begin{array}{l}16 \text { put } \\
\text { her }\end{array}$ & $18 \frac{1}{5}-g$. & 22 & 78 & 102 & $\begin{array}{c}\text { normal } \\
\text { eggs }\end{array}$ \\
\hline \& 3 & 4 & failed & - & 9 lost & 一 & - & - \\
\hline 우 4 & 4 & 16 put $\delta 13$ to & 30 b., $31 \frac{1}{4}-g$. & 35 & - & - & $\begin{array}{l}\text { no eggs laid, } \text { ? } \\
\text { alone at first, } \\
\text { approached by } \\
\text { ô } 13\end{array}$ \\
\hline 95 & 4 & 11 sought $\delta 9$ & - & 18 & 77 & 102 & $\begin{array}{l}\text { approached } \delta \text { on } \\
\text { days } 8-10 ; \text { few } \\
\text { eggs } h .\end{array}$ \\
\hline 96 & 4 & 9 sought $\delta 10$ & 20 t.g., 23 f. & 26 & 96 & 104 & $\begin{array}{l}\text { left by } \sigma^{*} \text { on } 25 \text { th ; } \\
\text { few eggs } h \text {. }\end{array}$ \\
\hline 우 7 & 4 & $\begin{array}{l}11 \text { put to } \delta 3 \\
\text { but left; } 12 \\
\text { put to } \delta 5\end{array}$ & $\begin{array}{l}16 \text { b., } 19 \frac{1}{4}-g ., 20 \\
\frac{1}{3} \text {-g. }\end{array}$ & $\begin{array}{ll}0 & 21\end{array}$ & 91 & 103 & $\begin{array}{r}\text { normal number } \\
\text { eggs; } q \text { got loose } \\
\text { but was replaced }\end{array}$ \\
\hline ㅇ 8 & 4 & Il sought ơ 1 & 18 t-g., 19 f. & 20 & - & - & died, laid no eggs \\
\hline 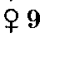 & 4 & 12 sought $\not 3$ & $\begin{array}{l}16 \mathrm{~b} ., 18 \frac{1}{3} \text {-g., } 19 \frac{1}{2}- \\
\text { g., } 20 \mathrm{f} .\end{array}$ & 21 & 83 & 89 & $\begin{array}{c}\text { normal } \\
\text { eggs }\end{array}$ \\
\hline q 10 & 4 & 11 sought $\delta 11$ & $20 \frac{1}{4}-\mathrm{g}$ & 21 & 80 & 108 & few eggs $h$. \\
\hline 이 11 & 11 & 11 put to o 7 & 18 b., 28 年-g., 33 & 37 & - & - & $\begin{array}{l}\text { fed v. slowly alone, } \\
\text { o } 7 \text { put to her } \\
31 \text { st, copulated; } \\
\text { she died without } \\
\text { laying }\end{array}$ \\
\hline 우 12 & 4 & 11 sought ot 2 & $18 \mathrm{f}$ & 20 & - & $一$ & few eggs, none $h$. \\
\hline 우 13 & 12 & 12 put to ${ }^{3} 4$ & $\begin{array}{l}16 \text { b., } 19 \frac{1}{\frac{1}{3}-g . g .}, 21 \\
\end{array}$ & 122 & 83 & 103 & $\begin{array}{c}\text { normal number } \\
\text { eggs }\end{array}$ \\
\hline q 14 & 12 & 12 put to $\delta^{A} 6$ & $19 \frac{1}{5}-g$ & 22 & 95 & 103 & few eggs $h$. \\
\hline 古 15 & 10 & 20 sought $\delta 9$ & 23 b., 26 t-g., 28 f. & f. $\quad 29$ & - & - & $*$ \\
\hline Q 16 & 10 & $\begin{array}{l}22 \text { sought } \delta * 11 ; \\
29 \text { sought } \delta 10\end{array}$ & $26 \frac{1}{4}-g$. & 31 & 85 & 110 & $\begin{array}{l}\text { normal number } \\
\text { eggs laid though } \\
\text { torn loose acci- } \\
\text { dentally }\end{array}$ \\
\hline ㅇ 17 & 12 & failed & 一 & - & - & - & $\begin{array}{l}\text { torn off 23rd, died } \\
\text { 99th, laid few } \\
\text { eggs }\end{array}$ \\
\hline ㅇ 18 & 19 & $\begin{array}{l}20 \text { approached } \\
\text { and } 22 \text { sought } \\
\delta 2\end{array}$ & $24 \frac{1}{4}$ g., 25 f. & 29 & - & - & $\begin{array}{l}\text { few eggs laid, none } \\
\text { h. }\end{array}$ \\
\hline 우 19 & 23 & 23 put to $\hat{o} 3$ & $28 \frac{1}{5} \cdot g ., 29 \frac{1}{3}$-g., $30 \mathrm{f}$ & f. 31 & 106 & 121 & few eggs $h$. \\
\hline ㅇ 20 & 23 & 23 put to of 4 & $\begin{array}{c}28 \frac{1}{5}-g ., 29 \frac{1}{3}-g ., 30 \\
\frac{1}{3}-g ., 31-2 \text { f. }\end{array}$ & $\begin{array}{ll}0 & 33\end{array}$ & - & - & $*$ \\
\hline 921 & 23 & 23 put to 8 & $\begin{array}{c}28 \frac{1}{5}-g ., 29 \frac{1}{3}-g ., 30 \\
\frac{1}{2}-g ., 31 \text { f. }\end{array}$ & $\begin{array}{ll}0 & 32\end{array}$ & 一 & 120 & $\begin{array}{l}\text { few eggs laid, few } \\
\text { h. }\end{array}$ \\
\hline ㅇ 22 & 23 & 23 put to of 6 & $\begin{array}{l}28 \frac{1}{5}-\mathrm{g} ., 29 \frac{1}{3} \cdot g ., 30 \\
\frac{1}{3} \text {-g., } 31 \mathrm{f} .\end{array}$ & $\begin{array}{ll}0 & 32\end{array}$ & 108 & 123 & $\begin{array}{c}\text { normal number } \\
\text { eggs }\end{array}$ \\
\hline 우 $\mathbf{2 3}$ & 39 & 39 put to of 2 & $45 \frac{1}{4}-\mathrm{g} ., 47 \frac{1}{2}-\mathrm{g}$ & 50 & 一 & - & $\begin{array}{l}\text { few eggs laid, none } \\
\text { h. }\end{array}$ \\
\hline ㅇ $\mathbf{2 4}$ & 39 & 39 put to o 3 & $45 \frac{1}{4}-g ., 47 \frac{1}{2}-g$. & 50 & 一 & - & $*$ \\
\hline+25 & 39 & 39 put to of 4 & $\begin{array}{l}45 \frac{1}{4} \text {-g., } 46 \text { 1-g., } 47 \\
\frac{1}{2}-g .\end{array}$ & $\begin{array}{ll}7 & 48\end{array}$ & 一 & - & $*$ \\
\hline+26 & 39 & 39 put to o 8 & $\begin{array}{l}45 \frac{1}{4}-g ., 46 \frac{1}{4}-g ., 47 \\
\frac{1}{2}-g .\end{array}$ & $7 \quad 49$ & - & - & no eggs $h$. \\
\hline 927 & 39 & 40 sought o 14 & $45 \mathrm{~b}$. & 49 & - & 131 & few eggs $h$. \\
\hline i 28 & 39 & 49 sought of 10 & $54 \frac{1}{3}$-g., 56 f. & 56 & 一 & - & $\begin{array}{l}\text { she came } 3 \mathrm{~cm} \text {. } \\
\text { from anchorage } \\
\text { to find } \delta^{\pi}\end{array}$ \\
\hline
\end{tabular}

Note. Copulation was observed to take place in the case of $q 5$ on days 11 and $12, q 11$ on day 31 , ㅇ 16 on day 22 , $q 28$ on day 49 .

* The $P$ was not allowed to oviposit. 
The foregoing protocols demonstrate the following regarding $A$. hebraeum:

Males. Of $13 \hat{d}+{ }^{t}$ one died on the 51 st day, one was removed and figured on the 77th day, six were lively when removed on the 132nd day, one was lost on the 136th day, and four were lively when removed on the 141st day.

The males with few exceptions do not move or scarcely move from their seat of attachment upon the host. Thus o 1 shifted ca. $2 \mathrm{~mm}$. on day 39 and remained fixed till day 132; ot $^{2}$ and $t 4$ remained on one spot for 141 days; ot 3 shifted a few $\mathrm{mm}$. on the 57th after which he remained fixed till day 141; o 5 shifted $1 \mathrm{~cm}$. on the $23 \mathrm{rd}, 3 \mathrm{~mm}$. on the $37 \mathrm{th}$, he was removed on the $77 \mathrm{th}$; o 6 shifted slightly on the $6 \mathrm{th}, 6 \mathrm{~mm}$. the $54 \mathrm{th}$, afterwards remaining fixed to the 141st; 07 wandered around the scrotum on the 37 th, shifted slightly on the 49th, wandered on the 50th and was dead on the 5lst; ${ }^{A} 8$ shifted $1 \mathrm{~cm}$. with his female on the 11th, and $8 \mathrm{~mm}$. on the $57 \mathrm{th}$, and remained fixed afterwards until the 132nd ; 0 s shifted $1 \mathrm{~cm}$. with his female on the 11 th, $7 \mathrm{~mm}$. the $51 \mathrm{st} ;{ }^{7} .10$ shifted $5 \mathrm{~mm}$. on the $25 \mathrm{th}, 13 \mathrm{~mm}$. on the $29 \mathrm{th}$, $5 \mathrm{~mm}$. on the 49th and again on the 99th, remaining fixed till the 132nd; ot 11 was slightly displaced by a male on the $29 t h$, then remained fixed till the 132nd; ot 13 shifted $3 \mathrm{~mm}$. on the 19th, $3 \mathrm{~mm}$. on the $21 \mathrm{st}, 5 \mathrm{~mm}$. on the 57th, slightly on the 99th afterwards remaining on one spot to the 132nd; ot 14 shifted $5 \mathrm{~cm}$. on the $22 \mathrm{nd}$, but remained fixed afterwards to the $132 \mathrm{nd}$. day. On two occasions males shifted in company with their females.

Males readily attach themselves in the absence of females. The males are sought by the females. When ready for copulation the males extend their legs and erect their bodies so as to seize and hold a passing female. Males frequently exhibit this sexual excitement when the skin of the host is touched or moved, no female being in the vicinity. Such males are described as "excited" in the protocols. In many instances virgin females were put to such expeotant males who promptly seized them, the females subsequently anchoring themselves on the same spot with the males.

The act of copulation was observed on five occasions, it occurs as I have described elsewhere for Ornithodorus and Ixodes 1 . A male may pair with several females, a fact recorded by L. and J. Roberts (see Nuttall, p. 414). My records show that $\delta^{\star} 3$ paired with four females, o 2 , o 4 , o 6 and o 10 with three females each, etc. $\delta 3$ fertilized three females, of $6, \delta 10$ and ot 11 fertilized two females each, whilst ot 2 failed to fertilize three females.

Males remain upon the host long after the females have dropped off gorged. Whilst they remain for days without changing their orientation, they may rotate slightly $\left(10-45^{\circ}\right)$ about the seat of the puncture in which their mouthparts are fixed.

The colour of the males undergoes a remarkable change as the result of a prolonged stay upon the host, the colour change was very distinct by the 77th day, still more so on the 131-141st day. The colour changes observed will be described in a further communication.

1 Nuttall and Merriman, 1911, Parasitology, rv. pp. 39-44, 1 fig.; Nuttall, Ibid. vr. p. 81 
Females. Of 28 우 under observation, one was lost, one was torn loose by accident, and 26 became engorged. Of these four were killed and preserved, leaving 22 of which six yielded normal progenies, seven yielded eggs few of which hatched, five laid eggs that did not hatch, whilst four died without ovipositing.

That females will not as a rule attach themselves in the absence of males was observed by Lounsbury (see Nuttall, p. 414). The females settle down to feed near males, and usually after $2-8$ or more days, they wander about, as I have found, in search of anchored males which seize them as they approach. Females may seek two males in succession, but one male usually suffices. Females feed slowly in the absence of males. The rate at which females become engorged varies even when they are paired. From the time when they show the first naked eye signs of feeding, it usually takes 4-5-6 days before they drop off fully gorged, but this period may be prolonged to 19 or more days ${ }^{1}$. The female swells gradually so that she appears successively " $\frac{1}{5}$," " $\frac{1}{4}$ " or " $\frac{1}{2}$-gorged" (as recorded in the protocols), whereas the fully gorged condition is reached rapidly. A female may imbibe as much blood in a few hours, prior to dropping off, as during several previous days. She usually drops off promptly when fully gorged, but there may be a delay of 24 hours or so possibly owing to difficulty in releasing her mouthparts.

\section{HYALOMMA AEGYPTIUM.}

The general biology of this species has been considered in previous papers (1915-16, Parasitology, vi. pp. 105-110; vII. p. 436).

The adults (Lot N. 1305) used in the following experiments belonged to the same strain used in my earlier observations (loc. cit.). They were fed upon a hedgehog as nymphs, and emerged as adults on 3-6. vii. 1914. There were some hundreds alive after being kept unfed at room temperature for 208 days. A number of these ticks were placed upon the ram's scrotum as follows:

\begin{tabular}{|c|c|c|c|}
\hline \multirow{3}{*}{ On 27. i. 1915} & $\begin{array}{l}\text { Day recorded } \\
\text { in protocol }\end{array}$ & & \\
\hline & 1 & 8 & 8 (9 6 was lost) \\
\hline & 17 & - & 1 (q 9 to replace $q 6$ ) \\
\hline
\end{tabular}

The following record relates therefore to $8 \sigma^{*}$ and 8 of and their behaviour upon the host on successive days:

Records relating to $H$. aegyptium Males Nos. 1-8.

ơ 1. Days 1-122 fixed, i.e. the male never moved from his first point of attachment in the right inguinal space outside the bag. Only one female escaped from the bag during the experiment, attaching herself in the opposite inguinal space.

ơ 2. Days 1-29 fixed, though a $q$ attached herself close by; between 30 th and 133rd day he altered his anchorage slightly on three occasions, moving 11,4 , and $4 \mathrm{~mm}$. respectively.

1 Lounsbury (Nuttall, p. 418) saw females remain as long as 25 days attached to the legs and feet of goats. He attributes these differences to the varying blood supply obtained by the tick in different situations upon the host. 
A 3. Days 1-7 fixed; on the 8 th he had shifted $5 \mathrm{~cm}$. to join $q 5$ with which he was seen to copulate on the 11th; she dropped on the 13th and he stayed fixed on the same spot until day 64 when he was removed.

* 4. Days 1-5 fixed; on 6 th had shifted $4 \mathrm{~cm}$. to join 97 which dropped on 12 th whilst he remained fixed until 13 th; on 14 th he shifted $10 \mathrm{~cm}$. to back of scrotum joining $q 3$ which he abandoned on $20 \mathrm{th}$, anchoring himself $12 \mathrm{~mm}$. away where he remained fixed till 30 th when heshifted $13 \mathrm{~cm}$. to front of scrotum; he subsequently anchored himself on seven different spots within a circle of $3.5 \mathrm{~cm}$. diameter, after having moved $18 \mathrm{~mm}$. on 33rd, $22 \mathrm{~mm}$. on $35 \mathrm{th}$, $11 \mathrm{~mm}$. on 45th, $24 \mathrm{~mm}$. on 54th, $1 \mathrm{~cm}$. on $56 \mathrm{th}, 6 \mathrm{~mm}$. on $120 \mathrm{th}, 2 \mathrm{~cm}$. on $139 \mathrm{th}$ day.

วิ 5. Days 1-5 fixed; on 6th had shifted $4 \mathrm{~cm}$. to join 92 which he abandoned on $13 \mathrm{th}$, being found anchored in front of scrotum $8 \mathrm{~cm}$. away. He remained fixed and alone, shifted $10 \mathrm{~cm}$. to back of scrotum on 17 th and remained fixed till 22 nd when he was found wandering and excited; he was now put to anchored 99 which he fertilized. This female dropped on 27 th but he stayed fixed till 36 th jwhen he shifted $15 \mathrm{~mm}$, after which he shifted 4, 10, 14, 8 and $5 \mathrm{~mm}$. respectively according to records made on days $48,51,110,121,139$.

o 6. Days 1-4 fixed; on 6th had shifted $3.5 \mathrm{~cm}$. to join 98 ; on 11 th copulated and on $13 \mathrm{th}$ abandoned her, shifting $9 \mathrm{~cm}$. to front of scrotum; ost on 14th.

đ7. Days 1-10 fixed; on 11th had shifted $3.5 \mathrm{~cm}$. to join 94 (copula); on 13th had abandoned her and shifted $16 \mathrm{~cm}$. to front of scrotum; on 19 th he had shifted $13 \mathrm{~mm}$., after which he shifted four times within a small area, i.e. $6,3,4$ and $5 \mathrm{~mm}$. respectively on days $41,47,56$, 64, remaining afterwards fixed till 139th day.

ô 8. Days 1-14 fixed; on 15th shifted $7 \mathrm{~mm}$., on 21 st shifted $10 \mathrm{~mm}$. to near a $ᄋ$ with her male; on $23 \mathrm{rd}$ shifted $9 \mathrm{~mm}$, on 24 th shifted $5 \mathrm{~cm}$. to front of scrotum, on 27 th shifted $11 \mathrm{~mm}$., and on 29 th $5 \mathrm{~cm}$. to back of scrotum; thereafter, always alone, he shifted nine times within a small area, i.e. $11,10,5,12,14,5,12,11$ and $10 \mathrm{~mm}$. respectively on days $36,38,47,52$, $56,61,97,121,123$, remaining fixed thereafter till 139 th day.

Records relating to $H$. aegyptium Females Nos. 1-9.

ๆ 1. Days 1-10 fixed, alone; on 10th nearly gorged, on 12th gorged. No $x$ was seen to approach but she was fertilized

$\begin{array}{ccc}\begin{array}{c}\text { Female } \\ \text { dropped } \\ \text { from host } \\ \text { on day }\end{array} & \begin{array}{c}\text { Female } \\ \text { ceaged } \\ \text { laying } \\ \text { on day }\end{array} & \begin{array}{c}\text { Eggs } \\ \text { began } \\ \text { to hatch } \\ \text { on day }\end{array}\end{array}$

. Days 1-5 fixed, alone; on 6th approached by o 5 ; on 7th gorged; on loth copula; on 13th the of gone

$18 \quad 65$

56

3. Days I-4 fixed, alone; on 11th slightly gorged; on 14th joined by $\sigma 4$, copulates and begins to feed; on 20 th $\hat{o}$ gone $\quad \ldots \quad \ldots$

†4. Days 1-10 fixed, alone; on 11th she joins 77 and copulates; on 13th of gone; on 18th she is fully gorged $\ldots \quad \ldots \quad \ldots \quad \ldots$

9 5. Days 1-7 fixed, alone; on 8th joined by 03 ; on 10 th she is $\frac{1}{4}$

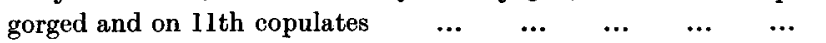

우 6. Lost

ㅇ 7. Days 1-5 fixed, alone; on 6th joined by 04 ; on 9th she is $\frac{1}{4}-$

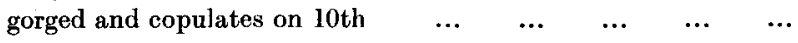

우 8. Days 1-2 fixed, alone, but near $\delta 5$; on 3-5th alone; on 6th joined by $\delta 6$; on 11 th copulates; on 13th ơ gone and she is partly gorged;

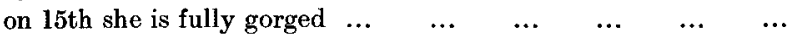

ㅇ 9. Put on ram on day 17 near $\delta 5$; on 20th alone; on 22nd put excited wandering $\delta 5$ to her; he stayed with her until she dropped and did not shift for days after. She dropped 27 th (10th day after being put on ram) 
The foregoing protocols demonstrate the following regarding $H$. aegyptium:

Males. $\delta 1$ remained isolated from females outside the bag and did not shift his position during 122 days. 02 remained fixed for 29 days and shifted three times afterwards between 30 th and 133rd days. $\delta \sigma^{*} 3-8$ remained fixed for $7,5,5,4,10$, and 14 days respectively before they sought females; o 6 was lost in his wanderings.

After a period of quiescence during which they indulged in a preliminary feed, the shifting about of the males was very pronounced as long as females were present. After the females had dropped off gorged, the males remained anchored within a very restricted area, shifting usually but a few $\mathrm{mm}$. at a time up to the 139th day, except in the case of 6 which was lost after the 14 th, and $\pi 3$ which was removed on the 64 th day.

of 5 sought two \& $ᄋ$, the rest sought but one $q$, but without doubt the males would have each sought several females had opportunity offered. The male may stay but a short time with a female or he may remain several days with her. After the female with which a male has mated abandons the host, the male may either wander away or remain attached for days or indefinitely at the same anchorage he occupied when the female was present. Females brought close to anchored males caused them to become greatly excited; a female ( 95 ) placed in the vicinity of a male, anchored herself beside him.

Females. With but one exception the females did not shift their anchorage from start to finish; they were all sought by males, with the possible exception of +4 , whilst, as previously stated, $q 5$ was placed near an excited male. The male that fertilized 91 remained with her so short a time that the union escaped observation. The females did not appear to copulate with more than one male. 우 2-9 dropped from the host $8,7,8,5,6,6$ days respectively after being approached by a male or having been seen to copulate. All of the females were fertilized and yielded a normal number of offspring.

\section{RHIPICEPHALUS BURSA.}

For an account of the general biology of this species, the reader is referred to my earlier papers (1913-15, Parasitology, vi. pp. 139-140; vII. pp. 438-448, $457-460)$.

The adults (Lot N. 1305a) used in the following experiments belonged to the same strain that was employed in my previous studies (loc. cit.). They had emerged 9. iii. 1914. On 26. i. 1915 there were some hundreds alive after having been kept unfed at room temperature for 323 days. The ticks were placed on the ram's scrotum in successive batches as follows:

On 26. i. 1915

\begin{tabular}{|c|c|c|}
\hline $\begin{array}{l}\text { Day recorded } \\
\text { in protocol }\end{array}$ & $\tilde{\sigma}$ & $q$ \\
\hline 1 & 11 & 11 \\
\hline 16 & - & 3 \\
\hline 18 & - & 3 \\
\hline Totals & 11 & 17 \\
\hline
\end{tabular}


All of the 17 of were fertilized and had plentiful offspring. Of the $\sigma^{\lambda} \sigma^{2}$, 1 anchored outside the bag and was lost on the 39th day, 1 died on 84th day, 3 were lost on the 98 th, 111th, and 122nd days respectively, leaving 6 that were removed in a lively condition on the 140th day, having paired with further females that had been added on the 128th day and which dropped off on the 137-140th day.

Owing to the glossy backs of the males, a few did not retain their marks, some confusion arose whereby the records were partly vitiated. A sufficiently accurate record could be kept, however, to form an idea regarding their general behaviour.

\section{Records relating to $R$. bursa Mxles 1-11.}

o 1. Days I-3 fixed; on 4th wandered; on 7th found with 95 with which he stayed till she dropped on the 9th and the $\delta$ was seen to walk away; on 11th approached $q 9$; on 12-16th alone and fixed; on 17-21st alone, having shifted around scrotum; on 22nd had wandered round scrotum to join 916 with which he stayed till she dropped on 29th; on 30th he had shifted slightly, remaining alone till 36th having shifted on 32nd; on 36th a semi-gorged female ( $q$ 17) was placed beside him, they remained near each other till she dropped on 4lst; on 42nd he had shifted, on 43rd he wandered round the scrotum and on 44-46th retraced his steps; on 48th shifted slightly and again on 52nd; he remained almost stationary till 60th, shifted round scrotum on 62 nd, remained fixed till 84 th when recording ceased.

f 2. Days 1-4 fixed; on 5th has joined 95 ; on 7 th shifted $3 \mathrm{~mm}$. to 94 which dropped on 10 th when he shifts downward to near $q 9$ which dropped on 13th; on 14th he approaches $q 11$ which dropped 16th; on 17-20th he was alone having wandered round the scrotum; on 21 st he shifted slightly and again 22nd; on 34th he wandered round the scrotum, upward on 37 th, downward on 38th, round scrotum on 39th, and shifted about further on days 43, 46, 55,58 , remaining fixed till the 62 nd day when he had wandered and could no longer be identified.

ô 3. Days 1-5 fixed; on 7th near $\delta 2$ and $q 4$ both of which were gone on 12th; on 14th he was near 911 with other males, she dropped 16th but he stayed on near the males till 19th when he ahifted round the scrotum after which he could not be identified.

The records of the other males are essentially similar and they need not be dwelt on. Suffice it to say that

f4. Sought 94 on the 4 th, ㅇ 11 on the 5th, 우 8 on the 7 th, 우 2 on the 12 th, approached 우 14 on the 18th, and $q 13$ on the 19th; he was only seen to copulate with $q 11$ and $q 13$.

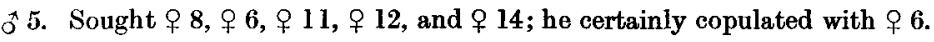

of 6-11. These merely afforded similar records to the foregoing but none of the males sought so many females and two of the males lost their markings at an early date.

Records relating to $R$. bursa Females 1-17.

ㅇ 1. Days 1-5 alone, fixed; on 7-9th joined by $\delta 8$...

\begin{tabular}{|c|c|c|}
\hline $\begin{array}{l}\text { Female } \\
\text { dropped } \\
\text { from host } \\
\text { on day }\end{array}$ & $\begin{array}{l}\text { Female } \\
\text { ceased } \\
\text { laying } \\
\text { on day }\end{array}$ & $\begin{array}{c}\text { Eggs } \\
\text { began } \\
\text { to hatch } \\
\text { on day }\end{array}$ \\
\hline
\end{tabular}

오 2. Days 1-7 alone, fixed; on 10th sought by ơ 4. Fully gorged on $\begin{array}{lllllllllll}11 \text { th } & \ldots & \ldots & \ldots & \ldots & \ldots & \ldots & \ldots & \ldots & \ldots\end{array}$

ㅇ 3. Days 1-3 alone, fixed; on 4th found with $\$ 4$. $\frac{1}{3}$-gorged on 10 th

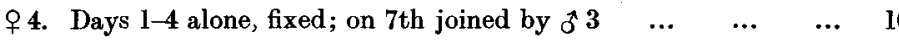

오.

ㅇ 6. Days 1-6 alone, fixed; on 7th joined by $\delta$. Fully gorged on 10-12th

$\begin{array}{rrr}9 & 40 & 46 \\ 14 & 45 & 46 \\ 12 & 43 & 46 \\ 10 & 40 & 47 \\ 9 & 41 & 46\end{array}$

$\begin{array}{rrrrrrrrrrrrr}\cdots & \cdots & \cdots & \cdots & \cdots & \cdots & \cdots & \ldots & 13 & 42 & 48 \\ & & & & & & & & \end{array}$


Records relating to $R$. bursa Females 1-17 (continued).

q 7. Days 1-5 alone, fixed; on 7-12th with a $\delta \quad \ldots \quad$...
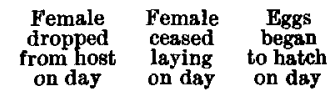

ㅇ 8. Days 1-5 alone, fixed; wandered and joined on 7 th by $f 4$.

ㅇ 9. Days 1-3 alone, fixed; lost 4th, found 5 th with 8 and afterwards with $\delta 1$, $\delta$. $\frac{1}{2}$-gorged on 10th, fully gorged on 11 th $\ldots \quad \ldots \quad 13$

우 10. Days 1-5 alone, fixed. $\frac{1}{2}$-gorged 10th, fully gorged 11th $\quad \ldots \quad 13 \quad 1342 \quad 48$

ㅇ 11. Days 1-4 alone, fixed; shifted and with $\$ 4$ on 5th. Fully gorged $\begin{array}{lllllllllll}\text { on } 8 \text { th } & \ldots & \ldots & \ldots & \ldots & \ldots & \ldots & \ldots & \ldots & \ldots\end{array}$

$16 \quad 43 \quad 46$

우 12. Put on 16th, with 5 on 17 th, alone 18th. $\frac{3}{4}$-gorged 23 rd, fully $\begin{array}{llllllllll}\text { gorged } 24 t h & \ldots & \ldots & \ldots & \ldots & \ldots & \ldots & \ldots & \ldots\end{array}$

우 13. Put on 16 th with a wandering $f$, on 17 th alone, on 19-20th with $\begin{array}{llllllll}\text { a } \delta \text {. } & \frac{3}{4} \text {-gorged on } 23 \mathrm{rd} & \ldots & \ldots & \ldots & \ldots & \ldots & \ldots\end{array}$

ㅇ 14. Put on 16th near $\delta^{*} 7$ with which she copulates 17th. $\frac{1}{3}$-gorged on 20 th

우 15. Put on 18th, alone 19th-22nd, found loose and wandering on 23rd when put to of 8 with which she copulates at once; act lasts 10 minutes; pair stay together till she drops, the male shifting next day

9 16. Put on 18th, alone till 22nd when joined by $\delta 1$; the pair stay together till she drops, four males surrounding them. $\frac{1}{3}$-gorged on 23rd

$\begin{array}{cccccccc}\ldots & \ldots & \ldots & \ldots & \ldots & \ldots & \ldots & \ldots \\ \text { 8th, found alone on thigh on } & 24 \text { th, on } & 35 \text { th found }\end{array}$

17. Put on 18th, found alone on thigh on 24th, on 35th found
wandering, on 36th put on scrotum and seen to anchor herself; on 37th there are $2 \delta^{*}$ close to her. $\frac{1}{4}$-gorged on 24th, 童-gorged on 39 th

The foregoing protocols demonstrate the following regarding $R$. bursa:

Males. After a preliminary feed lasting 3-5 days on one spot, the males wander in search of anchored females. Having found a female with which to copulate, the male frequently stays with her till she drops from the host and remains a day or so longer on the spot where the pair were attached. On the other hand the male may stay but a short time with a female, and seek a number of females in succession until he finds one with which to copulate. A number of males may congregate and anchor about a single female. The male may copulate with several females, a quiet feeding period of one or more days preceding copulation with a fresh female. The males wander about in search of females when no females are present upon the host, anchoring themselves in many different places for one or more days at a time. Males were observed to wander thus, in the absence of females, for a period of 86 days.

Females. All of the females were fertilized and yielded a numerous offspring. The females settle down to feed at once when placed on the host. They are sought by the males on the 4th-10th day, at times after 24 hours. A female may copulate with one or more males. 
SUMMARY.

Amblyomma hebraeum males anchor immediately when placed in a hungry state upon the host. The females will not do so as a rule in the absence of previously anchored males. Usually the males do not move or scarcely move when once anchored on the host, they may continue to remain attached to the host for months after the females have dropped off gorged. The males, after having fed for a few days, show signs of sexual excitement in that they erect their bodies away from the host and extend their legs, whereby, without releasing their mouthparts from the host's skin, they seize and hold any females that chance their way. The males become excited when the skin of the host in their vicinity is handled, no females having been near them for months. To copulate, the males must necessarily release their mouthparts, and this may at times lead to their shifting their position. They may occasionally shift to a fresh anchorage in company with their females, or they may shift a few $\mathrm{mm}$. when apparently alone. A male may copulate with several females. The coloration of the male changes after prolonged sojourn upon the host (77-141 days).

After feeding for 2-8 days or more, the females wander and are grasped by anchored males so that the ticks' ventral surfaces are apposed, and in this position the female proceeds to feed with her mouthparts puncturing the skin of the host in close proximity to those of the male. Copulation takes place in due course, the male temporarily removing his mouthparts from the host for the purpose. A female may seek two males in succession but usually one male appears to suffice. Females feed very slowly in the absence of males, they gorge rapidly when fertilized, and, when fully gorged, usually abandon the host without delay. Depending upon their having access to males and access to a more or less adequate food supply from the host, the females remain upon the host for 4-25 days before dropping off in a gorged condition.

Hyalomma aegyptium males anchor immediately when placed upon the host. In the absence of females they remain fixed or change their position but slightly at long intervals of time. When hungry males and females are placed together upon the host, they proceed to suck blood at once, and, after a preliminary feed lasting five or more days, the males wander in search of females. A male may copulate with several females. Females placed in close proximity to males cause these to become excited (as in $A$. hebraeum). The females as a rule do not change their anchorage upon the host from start to finish, being sought by the males. The latter stay upon the host indefinitely (122 or more days) after the gorged and fertilized females have dropped off.

Rhipicephalus bursa males and females, when hungry, proceed to feed at once when placed together upon the host. After remaining fixed for 3-5 days, the males seek anchored females. The males may seek a number of females in succession, usually feeding for some days prior to seeking a fresh female. 
Males continue to wander from anchorage to anchorage in the absence of females, they may thus wander about for 86 days or longer after the females have abandoned the host. A male may copulate with several females.

The behaviour of the sexes differs therefore in the three foregoing species. In $A$. hebraeum the females seek the males, in $H$. aegyptium and $R$. bursa the males seek the females. In all three species the males remain upon the host indefinitely after the females have dropped off. In $R$. bursa the males continue to wander about from anchorage to anchorage long after the females have left, whilst in $A$. hebraeum and $H$. aegyptium the males stop their wandering entirely or shift but slightly at longer intervals of time.

The predominance of male ticks of any species upon a host under natural conditions is accounted for by their staying on and accumulating upon the host whilst successive lots of females drop off. As an example I may mention that I have seen camels in Biskra on which only males of $H$. aegyptium could be found; these males must have been a very long time upon the camels because their scutums were polished and scratched, the rugose surface so characteristic of the young male tick having been worn away.

Copulation in all three species was observed on several occasions upon the host, the process lasted 10 minutes or longer and was similar to that described by me for Ornithodorus and Ixodes.

Since the liability to injury increases with the degree of engorgement of the female tick it is a great safeguard to her that she attains her full state of engorgement rapidly at the end of her feeding period and that she drops from the host promptly. 